\title{
Descentralización y regionalización en Chile 1974-2020: de la desconcentración autoritaria al Estado unitario descentralizado con mayor empoderamiento regional.
}

Decentralization and regionalization in Chile 1974-2020: from authoritarian deconcentration to a decentralized unitary state with greater regional empowerment.

Osvaldo Henríquez Opazo*

Resumen: El cambio en Chile del modelo de administración regional, se puede observar en diversas modificaciones constitucionales. En principio, la constitución de 1980 propone un modelo de Estado unitario descentralizado territorialmente, sin embargo, su diseño original fue organizado sobre las bases del modelo regional desconcentrado, creado a principios de los años 70, personificado en el intendente regional. A partir de la reforma constitucional de 1991 se configura un modelo normativo de descentralización territorial o mixto, cuyo eje central es el gobierno regional. Las reformas constitucionales de los años 2009 y 2017 eliminan la relación jerárquica entre el gobierno regional y el nivel central, a través de la democratización de los órganos que lo componen.

Palabras Clave: Descentralización territorial; Diseño constitucional; Transferencia de competencias; Cambio institucional.

\begin{abstract}
In Chile, the change of regional administration model, it's observed in its constitutional reforms. The Constitution (1980), proposes a territorially decentralized unitary State model. However, its design was organized on the basis of the centralist regional model, created in the early 1970s, centered in the regional intendant. The 1991 reform, created a new model, based in the normative, whose axis, is the regional government. The reforms of the years 2009 and 2017 eliminate the hierarchical relationship between the regional government and the central level. joined with its democratization.
\end{abstract}

Key Words: Territorial decentralization; Constitutional design; Attributions transfer; Instituional change.

Recibido: 6 mayo 2020 Aceptado, 5 agosto 2020

\footnotetext{
${ }^{*}$ El autor es Doctor del Programa problemas contemporáneos de la sociedad de la información de la Universidad Complutense de Madrid, Ha desarrollado su actividad académica en la Escuela de Ciencia Política y Administración Pública, Universidad de Talca. Ha sido profesor invitado en programas de postgrado de las universidades Católica de Temuco, Autónoma de Chile y Centro Heildelberg y ha participado en el proceso de discusión parlamentaria de las reformas constitucionales y leyes orgánicas asociadas del proceso de descentralización desde el año 2007 al año 2018. osvaldo.henriquez@utalca.cl
} 


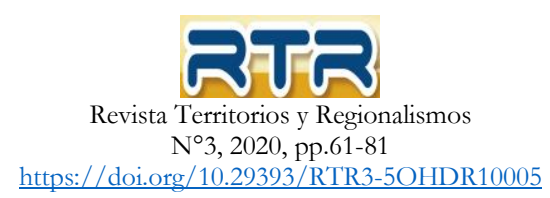

\section{1.- Introducción}

La descentralización en Chile es un tema que ha estado presente desde los inicios de la república, similar discusión se ha desarrollado en la mayoría de los países de América Latina ${ }^{1}$, cada país a través del tiempo ha definido sus propios arreglos institucionales y normativos. países como Brasil y Argentina, presentan formas federales con un alto grado de autonomía y descentralización, Entre los países unitarios 2 , se identifican países como Bolivia con estructuras constitucionales compuestas con altos niveles de descentralización territorial y modelos de estructura simple de mediano a bajo nivel de descentralización, entre ellos, Colombia, Ecuador y Perú y finalmente países como Costa Rica, Panamá, El Salvador cuya descentralización territorial tiene como eje el nivel municipal. Chile de acuerdo con su trayectoria ha sido identificado con este último grupo de países, considerándose como uno de los países más centralizados que integran la $\mathrm{OCDE}^{3}$. Sin embargo, en las últimas dos décadas, se ha venido modificando la constitución y las leyes, por lo cual, podemos señalar que ha pasado a formar parte de un grupo de países con características más descentralizadas, tales como Ecuador, Perú y Paraguay. Esta comparación, se refiere a cambios en sus diseños normativos. Es en este sentido, es importante caracterizar y, por lo tanto, describir el nuevo diseño constitucional y normativo aplicado en Chile de la descentralización territorial.

La discusión sobre la organización y forma del Estado, es un tema siempre vigente y de interés. En esta misma línea, la discusión sobre cómo se distribuye el poder del Estado, es poner en el debate el ejercicio del poder territorial, que puede ser centralizado o descentralizado. El primero correspondería a un ejercicio a través de una organización desconcentrada o descentralizada administrativamente, lo que equivale a una desconcentración de las estructuras y burocracias del gobierno central o delegación de la autoridad del gobierno central a entidades semiautónomas. El segundo, es la forma en que los ciudadanos aumentan su participación en la selección de representantes políticos y en la elaboración de políticas públicas, a la vez que experimentan cambios en la estructura de gobierno a través de la transferencia de potestades y autoridad a las unidades subnacionales ${ }^{4}$.

En el marco de estas definiciones, en Chile históricamente la descentralización ha sido un tema de tratamiento complejo. En el periodo de la vigencia de la constitución del año 1925 si bien fue su finalidad original, el constituyente fue en extremo receloso de consagrar mecanismos que dieran reales atribuciones a las provincias, ello también fue atenuado en su aplicación, por una tendencia favorable a la práctica del centralismo ${ }^{5}$. Sin embargo y en el marco de la constitución de 1980, se ha observado una evolución que va de un modelo históricamente centralizado y que ha presentado dificultades políticas ${ }^{6}$ y constitucionales $^{7}$ en el proceso de transición al nuevo modelo de descentralización territorial. En este estudio, se considerará como descentralización territorial aquella descrita en sus tres formas clásicas ${ }^{8}$. En primer lugar, la descentralización administrativa como en su régimen de competencias y proceso de transferencia; en segundo lugar, la descentralización política presentando su nuevo régimen electoral y finalmente la descentralización fiscal, a través de una descripción del gasto.

\footnotetext{
${ }^{1}$ Daughters R. \& Harpers L (2007), p. 243.

${ }^{2}$ Barrios-Suvelza F. (2014), p. 15: 19.

${ }^{3}$ OCDE (2015).

${ }^{4}$ Shabbir, Cheema y Rondinelli (2007)

${ }^{5}$ Carrasco Delgado S. (1997), p.334.

${ }^{6}$ Mardones R. (2006), p. 19

${ }^{7}$ Tsibelis G. (2018), p. 27

${ }^{8}$ Falleti T. (2010)
} 


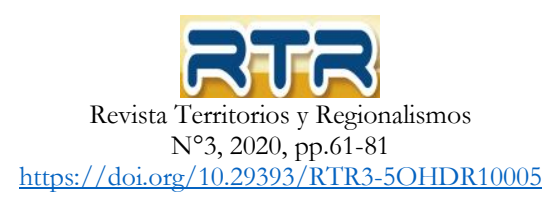

En el marco de la constitución de 1980 y la reforma ${ }^{9}$ del año 1991, se ha planteado que ha sido un cambio de envergadura y relevancia ${ }^{10}$, ello referido principalmente a una innovación estructural y conlleva una adecuación a la ley de Bases Generales de la Administración del Estado al conformarse un nuevo órgano en la administración denominado gobierno regional ${ }^{11}$ creados en el año 1993 mediante la ley orgánica de gobierno y administración regional Ley $\mathrm{N}^{\mathrm{o}} 19.175$ iniciando con ello, un nuevo diseño institucional en la administración regional donde convivirá una institución descentralizada territorialmente con la administración nacional desconcentrada. El proceso predominante ${ }^{12}$ es la descentralización administrativa $^{13}$ hasta la reforma constitucional ${ }^{14}$ del año 2009 que propone la elección por sufragio universal ${ }^{15}$ de los consejeros regionales y profundiza la descentralización administrativa ${ }^{16}$ a través de la transferencia de competencias. La estructuración de la descentralización territorial se concreta mediante la reforma ${ }^{17}$ del año 2017 en que pasa de un modelo jerárquico a un modelo de descentralización tutelado ${ }^{18}$ y profundiza la descentralización política a través de la elección por sufragio universal ${ }^{19}$ del gobernador regional.

\section{2.- Recorrido histórico}

La correcta descripción del modelo de descentralización territorial lleva a revisar la historia del proceso, en particular sobre la creación y conformación del nivel intermedio en Chile. En el país, dicho nivel corresponde a la región que pasa a formar parte de la nueva división político-administrativa creada en el año 1974 a través de la publicación de los decretos DL 573 y 575. El fundamento de este proceso surge de diversos estudios realizados en la década de los años sesenta retomados por la Comisión Nacional de la Reforma Administrativa (CONARA) que tenían como objetivo revisar la organización de la administración del Estado de la época y sus estructuras con el objetivo de mejorar la gestión administrativa mediante métodos y sistemas racionales, que aseguraran una alta productividad y optimización de las tareas de gobierno (CONARA, 1974). Es así como en el D.L.573 establece que la organización interna ${ }^{20}$ del gobierno puede guiarse por criterios de descentralización y desconcentración y no se contrapone con el Estado unitario.

La organización de la administración del Estado en Chile, se instituye a partir del año 1974 en el proceso conocido como "la regionalización" 21 , sobre la base de las regiones recién creadas se superpone una administración regional desconcentrada. El modelo "Regional Desconcentrado" tendrá vigencia entre 1974 y 1991 que propone la unión de las competencias de gobierno y de administración superior de cada región reside en la figura del intendente regional, quien ejerce sus funciones en el marco de las instrucciones del poder ejecutivo. En el territorio se emplazan las oficinas desconcentradas de ministerios denominadas secretarias regionales ministeriales (seremi) y también servicios públicos conocidas como

\footnotetext{
${ }^{9}$ Reforma Constitucional (1991), Ley 19.097.

${ }^{10}$ Cea Egaña J. (1997), p.343

${ }^{11}$ Hernández Olmedo L. (1993), p. 549.

12 Navarrete B. (2014), p. 186.

13 Incremento de las funciones administrativas de los gobiernos regionales mediante ley 20.035/2005

14 Reforma Constitucional (2009), Ley 20.390.

${ }^{15}$ Regulada por Ley No20.678 (2013)

${ }^{16}$ Regula la transferencia de competencias a los gobiernos regionales, Ley 21074 (2018)

${ }^{17}$ Reforma Constitucional (2017), Ley 20.990

${ }_{18}$ Nogueira Alcalá H. (1985), p.136.

${ }^{19}$ Regulada por ley 21074 (2018)

20 "Para el gobierno y la administración interiores del Estado, el territorio de la república se dividirá en regiones y las regiones en provincias. Para los efectos de la administración local, las provincias se dividirán en comunas" (artículo 1, DL573).

${ }^{21}$ DL N573 (1974)
} 


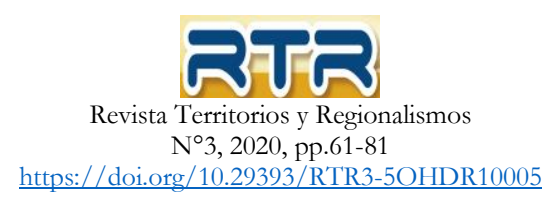

direcciones regionales. Seis años después la nueva constitución conocida como "la Constitución del 80" reconoce dicho modelo y además propone que éste evolucione en el marco de un Estado unitario y las regiones propendan hacia una administración funcional y territorialmente descentralizada.

Una década después y en el marco de la reforma a la norma constitucional realizada en el año 1991 en materias de gobierno regional y administración comunal, mantiene el concepto de descentralización territorial en el nivel regional, pero modifica el diseño original varían a un modelo "Regional Mixto" que predominará los siguientes 25 años. El nuevo modelo consiste en la convivencia entre la descentralización territorial normativa, centrado en el nuevo gobierno regional y el modelo de desconcentración preexistente. Sin embargo, produce la separación de la función de gobierno y la función de administración superior de la región. Asignando al intendente regional (Ley 19.097, 1991: Art. 7) la primera y la segunda, al gobierno regional (Ley 19.097, 1991: Art. 7) 22 institución creada para el efecto integrada por el intendente y el consejo regional. El nuevo modelo, es asimilable al de descentralización del tipo administrativa que estará vigente hasta el año 2017. Ello se enfatiza, cuando existe una delegación de la autoridad del gobierno central, en la administración regional, a una entidad semiautónoma ${ }^{23}$, el gobierno regional. En la nueva norma constitucional ${ }^{24}$ reformada, propone un nuevo mecanismo, que permita transferir poder a las regiones a través de la descentralización administrativa y se denominará "transferencia de competencia" 25 lo anterior siempre buscando la debida coordinación entre los órganos de la administración, lo que se regula con posterioridad en la ley 19.175 del año 1992.

El modelo definido en la norma permitía a los gobiernos regionales solicitar la transferencia de competencias y recursos en el sentido de avanzar en el proceso de descentralización, sin embargo, el articulado presentado en 1992 no definió un procedimiento aplicable con posterioridad a la consideración del Presidente de la República de la solicitud de transferencia de competencia. En tal situación, es dable entender que en el caso de considerar admisible tal iniciativa, ello se debería traducir en el envío de un proyecto de ley al Congreso Nacional por el Presidente de la República en el ejercicio de sus atribuciones. En el periodo 1993 a 2006 no se identifican solicitudes provenientes de los gobiernos regionales, pero si se pueden encontrar competencias transferidas por iniciativa del Presidente de la República mediante modificaciones de la ley 19.175 y otros cuerpos legales (ver tabla $\mathrm{N}^{\circ} 1$ ).

\footnotetext{
22 El gobierno regional se define como una institución descentralizada territorialmente, con patrimonio propio y persona jurídica distinta de la del Estado, lo que lo configura como un ente descentralizado normativamente.

${ }^{23}$ Se entiende semiautónoma producto que el Intendente en su calidad de Presidente del Consejo Regional y Ejecutivo del gobierno regional es una autoridad designada por el Presidente de la República.

24 Artículo 103 de la CPR 1980 modificación introducida por la ley 19.097

${ }^{25}$ Ley 19.175 (1993), Art. 67 “Los gobiernos regionales, para los efectos de lo previsto en el artículo 103 de la constitución política de la República, podrán solicitar al Presidente de la República el traspaso de competencias y recursos que estén a cargo del organismos o servicios de la administración central o funcionalmente descentralizada, acompañado al efecto los estudios y antecedentes que demuestren su aptitud para asumir tales responsabilidades.

Los antecedentes serán analizados por los ministerios y servicios públicos involucrados, los que deberán evacuar un informe dentro de los sesenta días siguientes a la recepción de la documentación respectiva.

Dicho informe y el que, a su vez, deberá expedir el ministerio del interior, serán entregados al Presidente de la República para su consideración sobre la materia.
} 
TABLA No1

Ejemplos de competencias transferidas a los gobierno regionales vía ley por iniciativa presidencial.

\begin{tabular}{|l|c|c|}
\hline \multicolumn{1}{|c|}{ COMPETENCIA } & AÑ & LEY \\
\hline $\begin{array}{l}\text { Aprobar los planes regionales de desarrollo urbano, los planes } \\
\text { reguladores metropolitanos y los planes seccionales regulados por } \\
\text { la ley general de urbanismo y construcciones. }\end{array}$ & 2001 & 19.778 \\
\hline $\begin{array}{l}\text { Construir, reponer, conservar y administrar en las áreas urbanas las } \\
\text { obras de pavimentación de aceras y calzadas, con cargo a los fondos } \\
\text { que al efecto le asigne la ley de presupuestos }{ }^{26} \text {. }\end{array}$ & 2005 & 20.035 \\
\hline $\begin{array}{l}\text { Se faculta al Intendente Regional en su calidad de ejecutivo del } \\
\text { gobierno regional, que durante el primer trimestre de cada año } \\
\text { elaborará el ante proyecto regional de inversiones (ARI). }\end{array}$ & 2005 & 20.035 \\
\hline $\begin{array}{l}\text { El Fondo Nacional de Desarrollo Regional es un programa de } \\
\text { inversiones públicas, con finalidad de desarrollo regional... }\end{array}$ & 2005 & 20.035 \\
\hline $\begin{array}{l}\text { Los gobiernos regionales podrán asociarse con otras personas } \\
\text { jurídicas, para constituir con ellas corporaciones o fundaciones de } \\
\text { derecho privado destinadas a propiciar actividades o iniciativas sin } \\
\text { fines de lucro, que contribuyan al desarrollo regional. }\end{array}$ & 2005 & 20.035 \\
\hline $\begin{array}{l}\text { Declaración de áreas preferenciales de pesca recreativa y otras } \\
\text { materias... }\end{array}$ & 2008 & 20.256 \\
\hline $\begin{array}{l}\text { Emitir el informe de compatibilidad territorial de proyectos } \\
\text { presentados en el sistema de evaluación ambiental. }\end{array}$ & 2014 & 20.417 \\
\hline $\begin{array}{l}\text { Aprobar los planes de detalle... (Ley General de Urbanismo y } \\
\text { Construcciones) }\end{array}$ & 2014 & 20.791 \\
\hline $\begin{array}{l}\text { Elaborar y aprobar los planes de inversiones en infraestructura de } \\
\text { movilidad y espacio público... }\end{array}$ & 2016 \\
\hline $\begin{array}{l}\text { Seleccionar, fundadamente, los proyectos beneficiados con los } \\
\text { recursos para financiar servicios sanitarios rurales. }\end{array}$ & 2017 \\
\hline
\end{tabular}

Fuente: Elaboración propia en base a modificaciones de la ley 19.175, ley19.778 y ley 20.035.

Como se puede observar las competencias descritas en la tabla $\mathrm{N}^{\circ} 1$, en el periodo que va desde el año 1993 al año 2017 el Presidente de la República transfirió a los gobiernos regionales un total de 10 competencias, cuyo origen es sectorial y mayoritariamente son de transporte y urbanismo (4); así como también del sector obras públicas (1), pesca (1) y medio ambiente (1). En materia presupuestaria y financieras, por otro lado, se transfieren dos competencias y una competencia genérica relacionada con asociativismo. Otra forma para avanzar en la descentralización administrativa consistió en la utilización de la Ley de Presupuestos del Sector Público, transfiriendo competencias a los gobiernos regionales de forma temporal ${ }^{27}$, también se expresaba en ella la voluntad del Presidente de la República, algunos ejemplos de aquello se exponen en la Tabla $\mathrm{N}^{\circ} 2$.

${ }^{26}$ La competencia señalada debe ser complementada con la revisión del DFL2/19.175 del año 2005

${ }^{27} \mathrm{La}$ temporalidad de la ley de presupuestos del sector público equivale a un año, las competencias transferidas a los gobiernos regionales, por lo general, se renovaban año a año. 


\section{RTR \\ Revista Territorios y Regionalismos \\ N³, 2020, pp.61-81 \\ https://doi.org/10.29393/RTR3-5OHDR10005}

TABLA No2

Ejemplos de competencias transferidas a los gobiernos regionales a través de la ley de Presupuestos del Sector Público.

\begin{tabular}{|l|c|c|}
\hline \multicolumn{1}{|c|}{ COMPETENCIA } & AÑ & LEY \\
\hline $\begin{array}{l}\text { Financiar proyectos postulados por las universidades de la región } \\
\text { que no comprometan gastos futuros de los Gobiernos Regionales. }\end{array}$ & 1991 & 19.540 \\
\hline $\begin{array}{l}\text { Los Gobiernos Regionales podrán transferir recursos a } \\
\text { instituciones públicas para el financiamiento de programas de } \\
\text { fomento productivo, los que se regirán por la normativa legal de la } \\
\text { institución receptora. }\end{array}$ & 2001 & 19.702 \\
\hline $\begin{array}{l}\text { Con estos recursos se podrán financiar programas de recuperación } \\
\text { de áreas urbanas patrimoniales, en conjunto con el sector privado. }\end{array}$ & 2001 & 19.702 \\
\hline $\begin{array}{l}\text { Proponer a las instituciones públicas que definan y ejecuten } \\
\text { programas de fomento productivo y de capacitación en el mes de } \\
\text { diciembre del año 2001. }\end{array}$ & 2002 & 19.774 \\
\hline $\begin{array}{l}\text { Financiar proyectos construcción, reparación y equipamiento } \\
\text { presentados por las compañías de bomberos de la respectiva región. }\end{array}$ & 2002 & 19.774 \\
\hline $\begin{array}{l}\text { Financiar proyectos de agua potable rural, transfiriendo la } \\
\text { infraestructura a los beneficiarios. }\end{array}$ & 2003 & 19.842 \\
\hline $\begin{array}{l}\text { Financiar la publicación de los planes reguladores aprobados por el } \\
\text { respectivo gobierno regional. }\end{array}$ & 2003 & 19.842 \\
\hline $\begin{array}{l}\text { Financiar inversiones en construcción, habilitación, conservación y } \\
\text { mejoramiento de caminos comunitarios ubicados en territorios } \\
\text { definidos en la ley indígena. }\end{array}$ & 2004 & 19.986 \\
\hline $\begin{array}{l}\text { El gobierno regional podrá financiar hasta el 1\% del total de los } \\
\text { recursos de su presupuesto, para subvencionar actividades de } \\
\text { carácter cultural que determine }\end{array}$ & 2004 & \\
\hline
\end{tabular}

Fuente: Elaborada en base a leyes de presupuestos del sector público entre los años 1999 y 2004.

Es importante señalar entonces, que si bien, las competencias transferidas en la ley de presupuestos son eminentemente temporales y su vigencia es de un año, estará vigente en tanto sea considerada en leyes de presupuestos posteriores. La naturaleza de las competencias consignadas en la ley de presupuestos corresponde principalmente a materias del tipo financiero y relacionado con el destino y uso de los recursos. A modo de ejemplo, antes del año 2003 el gobierno regional no podría haber financiado proyectos de agua potable rural y transferir dicha infraestructura a sus beneficiarios como se especificó en la ley 19.842 como se puede observar en la tabla $\mathrm{N}^{\circ} 2$, lo mismo sucedía con el financiamiento de la publicación de los planes reguladores comunales aprobados por el gobierno regional. Es la ley de presupuestos, el principal instrumento de transferencia de competencias aumentando la autonomía administrativa del gobierno regional y a su vez, es el principal instrumento que promueve la descentralización fiscal.

A partir del año 2007, se puede observar un cambio en la cultural predominante y es posible identificar que los gobiernos regionales solicitaron al Presidente de la República la competencia de planificación del 


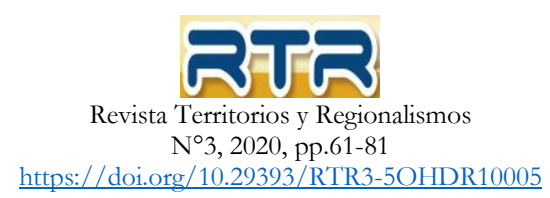

desarrollo regional ${ }^{28}$, competencia ejercida en aquel entonces por la secretaria regional ministerial de planificación órgano desconcentrado del ministerio de planificación ${ }^{29}$. Una revisión somera de los mecanismos de transferencia de competencias, entre ellos, la vía legislativa que implicaba preferentemente modificaciones a la ley 19.175 se concluiría que el ritmo no era del todo satisfactorio para avanzar en la descentralización administrativa a través de dicho mecanismo, por un lado, los gobiernos regionales no eran prolíficos en solicitar competencias, tal vez por la inhibición del intendente regional dado su calidad de funcionario dependiente del Presidente de la República o la reticencia de ministerios y servicios públicos de transferir su poder y recursos a los gobiernos regionales.

\subsection{Las propuestas de cambio en el periodo 2003-2017}

El avance de la descentralización administrativa ha sido lento ${ }^{30}$ y la transferencia de competencias escasas en el período 1993-2017, por cuanto ello, estaba supeditado al mecanismo de transferencia de competencias "vía ley" como lo señalaba la constitución política hasta el año 2009, "La ley deberá determinar las formas en que se descentralizará la administración del Estado, asi como la transferencia de competencias a los gobiernos regionales". Un primer intento de modificación ocurre en diciembre del año 2003 a través del mensaje ${ }^{31}$ del ejecutivo, que inicia un proyecto de reforma constitucional en materia de gobierno y administración regional, en el cuál, se propone modificar el artículo 103 vigente a la fecha por un mecanismo concreto para la transferencia de competencias "El Presidente de la República, de propia iniciativa y mediante decreto supremo, podrá transferir a uno o más gobiernos regionales, determinadas competencias del nivel central o de los servicios públicos que operen en la región, y los recursos y personal correspondientes al ejercicio de tales competencias, de conformidad al procedimiento establecido en la ley orgánica respectiva". La propuesta en esa oportunidad, en materia de descentralización administrativa es la utilización la vía reglamentaria por parte del Presidente de la República a través de decretos supremos como mecanismo para modificar las competencias ${ }^{32}$ sectoriales y transferirlas a los gobiernos regionales, mecanismo ${ }^{33}$ que se terminará regulando ${ }^{34}$ en el año 2018.

\section{a) Propuesta del Año 2008}

En el intertanto de la tramitación de la reforma constitucional aprobada por ley $20.390^{35}$ el año 2009 se propone una modificación legal a la ley 19.175 contenida en el boletín 5872-06 del mes de mayo del año 2008 cuyo objeto era el de proponer modificaciones al sistema de transferencia de competencias (ver

${ }^{28}$ En el marco del Programa Apoyo a la Gestión Subnacional (AGES) financiado por el Banco Interamericano de Desarrollo (BID) y administrado por la Subsecretaria de Desarrollo Regional y Administrativo (SUBDERE) que tenía entre sus objetivos promover la transferencia de competencias del nivel central al regional se identifican y promueve la transferencia de competencias, a través, de la aplicación de los artículos 67 y 107 de la ley 19.175.

${ }^{29}$ La competencia fue transferida en la ley 20.530 (2011) art. 23 de la ley 20.530 "A los gobiernos regionales corresponderán exclusivamente las funciones y atribuciones en materia de planificación del desarrollo de la Región, mediante el diseño, elaboración, aprobación y aplicación de políticas, planes y programas dentro de su territorio, los que deberán ajustarse a las políticas nacionales de desarrollo y al presupuesto de la Nación”.

${ }^{30}$ Se ha definido el proceso como lento y no gradual, dado que la gradualidad implicaría la existencia de un estado de llegada y ello no ocurre.

${ }^{31}$ El mensaje 47-350 del 11 de diciembre del año 2003, presentado en la sesión 34 de la legislatura 350

${ }^{32} \mathrm{La}$ competencia es el conjunto de facultades y poderes que se entregan a los órganos públicos o administrativos y permite al órgano relacionarse con los demás. Las mismas son precisadas por el ordenamiento jurídico. Los factores de la competencia son la materia, el territorio y el tiempo (Bermúdez, 2013)

${ }^{33}$ La ley 21.074 del año 2018 define que la transferencia se realizará mediante un decreto ejecutivo de transferencia.

${ }^{34}$ Ley 21.074 (2018), artículos 21 bis a 21 octies.

35 Dicha reforma se inicia en el mensaje 47-350 del año 2003 modificado por una indicación sustitutiva mediante mensaje del año 2007 


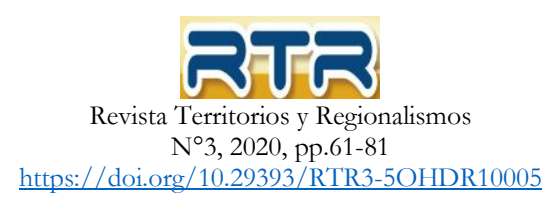

recuadro $\mathrm{N}^{\circ}$ ). El mecanismo considera la transferencia de competencias por parte del Presidente de la República a través de un decreto con fuerza de ley (DFL), en el caso que la competencia requiriera modificaciones legales y vía decreto supremo en el que no fuese requerida asimilándose al sistema de convenios establecidos en la ley 19.175 art.107 vigente a la fecha. La propuesta mencionada no fue tramitada quedando a la espera de la promulgación de la reforma constitucional que se discutía en paralelo.

Recuadro Nº1 Procedimiento propuesto por el Ejecutivo en mayo del 2008

\begin{tabular}{|c|c|}
\hline Materias & $\begin{array}{l}\text { Ordenamiento territorial; fomento de las actividades productivas; desarrollo } \\
\text { social y cultural. }\end{array}$ \\
\hline Temporalidad & $\begin{array}{l}\text { Definitiva y en forma excepcional se definirá como temporal si el comité así } \\
\text { lo recomienda. }\end{array}$ \\
\hline Precursor del proceso & Presidente de la República y Gobierno Regional \\
\hline Reglamentación & $\begin{array}{l}\text { Reglamento del ministerio del interior, hacienda y secretaria general de la } \\
\text { presidencia. }\end{array}$ \\
\hline $\begin{array}{l}\text { A solicitud } \\
\text { gobierno regional }\end{array}$ & $\begin{array}{l}\text { Periodo: en el primer trimestre de cada año } \\
\text { Iniciativa: Intendente Regional } \\
\text { Aprobación: Consejo Regional } 4 / 5 \\
\text { Revisión: Comité interministerial (ministerio del interior, hacienda, segpres, } \\
\text { ministerio sectorial y director de servicio. } \\
\text { Pronunciamiento: } 30 \text { días } \\
\text { Fortalecimiento de capacidades: Programa de apoyo de instalación de } \\
\text { capacidades de } 120 \text { días. } \\
\text { Transferencia de competencias: En el caso de requerir modificaciones legales } \\
\text { el Presidente de la República solicita al Congreso Nacional autorización para } \\
\text { emitir decreto con fuerza de ley que permita transferir la competencia. En el } \\
\text { caso de que la transferencia no requiera modificaciones legales, se transferir } \\
\text { mediante decreto supremo expedido por el Ministerio del interior y los } \\
\text { ministros correspondientes al sector. } \\
\text { Decreto: Deberá consignar las competencias transferidas, el recurso humano } \\
\text { y financiero requerido para el ejercicio de la competencia }\end{array}$ \\
\hline A propuesta & Periodo: Indefinido \\
\hline Ministerios y Servicios & Iniciativa: Ministerios y Servicios Públicos \\
\hline Públicos & $\begin{array}{l}\text { Aprobación: Presidente de la República previa recomendación comité de } \\
\text { ministros y consulta al gobierno regional } \\
\text { Pronunciamiento: } 30 \text { días } \\
\text { Fortalecimiento de Capacidades: Programa de apoyo de instalación de } \\
\text { capacidades de } 120 \text { días } \\
\text { Transferencia de Competencias: En el caso de requerir modificaciones legales } \\
\text { el Presidente de la República solicita al Congreso Nacional autorización para } \\
\text { emitir decreto con fuerza de ley que permita transferir la competencia. En el } \\
\text { caso de que la transferencia no requiera modificaciones legales, se transferir } \\
\text { mediante decreto supremo expedido por el Ministerio del interior y los } \\
\text { ministros correspondientes al sector. } \\
\text { Decreto: Deberán consignar las competencias transferidas, el recurso } \\
\text { humano y financiero requerido para el ejercicio de la competencia. }\end{array}$ \\
\hline
\end{tabular}




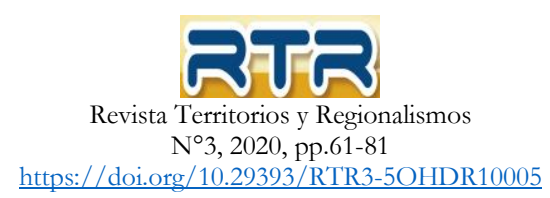

Transcurrido el año 2009 se aprueba una nueva la reforma constitucional que en lo sustancial modifica el artículo 114 (ex 103) en el siguiente tenor: "La ley orgánica constitucional respectiva determinará la forma y el modo en que el Presidente de la República podrá transferir a uno o más gobiernos regionales, en carácter temporal o definitivo, una o más competencias de los ministerios y servicios públicos creados para el cumplimiento de la función administrativa, en materias de ordenamiento territorial, fomento de las actividades productivas y desarrollo social y cultural". Acá se puede observar el interés del legislador de que la transferencia se adecúe a la realidad territorial permitiendo romper la homogeneidad institucional vigente hasta el momento considerado como principio fundamental en un Estado unitario, es decir, en adelante cada región podría tener su propio marco jurídico ${ }^{36}$.

\section{b) Propuesta del año 2011}

La propuesta del ejecutivo a través del mensaje presidencial ${ }^{37}$ (ver Recuadro $\mathrm{N}^{\circ} 2$ ) enviado con posterioridad a la reforma constitucional, éste propone un proceso simple en los requerimientos que pudieren surgir desde el gobierno regional, en ella se puede destacar el concepto que es el gobierno regional, el que debe gatillar el proceso y el gobierno central facilitarlo. La propuesta define un sistema de tres alternativas, el primero, la transferencia de atribuciones, el segundo, a través de programas y la tercera forma, corresponde a la creación de servicios públicos regionales, que serán definidos por una ley. Considera también, la opción de incorporar cambios en su estructura organizativa, a través de la solicitud de hasta 3 nuevas divisiones por el gobierno regional, que viene a complementar las ya existentes en el servicio administrativo. Un elemento relevante de esta propuesta, a parte de su simplicidad, es la de ampliar el alcance de los ámbitos de ordenamiento territorial, fomento de las actividades productivas y desarrollo social y cultural expresado en el artículo 114 de la constitución. El sentido de la propuesta era evitar una interpretación restrictiva por parte de la Contraloría General de la República de los ámbitos definidos en la norma constitucional remitiéndolo solo a los artículos previstos en la ley y que corresponden a los números 17, 18 y 19 de la ley 19.175. Se incorpora también, la opción de revocación ante el incumplimiento de lo convenido entre los ministerios y servicios públicos con el gobierno regional.

Recuadro N²: Procedimiento propuesto por el ejecutivo en septiembre del año 2011

\begin{tabular}{|l|l|}
\hline Materia & $\begin{array}{l}\text { Ordenamiento territorial; Planificación urbana y asentamientos humanos; medio } \\
\text { ambiente; obras de infraestructura y equipamiento regional, trasporte, desarrollo } \\
\text { rural y de localidades aisladas; fomento de las actividades productivas; turismo, } \\
\text { programas sociales y culturales; educación y salud; deporte; ciencia y tecnología y } \\
\text { conservación del patrimonio. }\end{array}$ \\
\hline Temporalidad & Temporal y definitiva según su naturaleza \\
\hline Precursor & Gobierno Regional \\
\hline Reglamentación & No hay \\
\hline $\begin{array}{l}\text { A solicitud del } \\
\text { gobierno } \\
\text { regional }\end{array}$ & $\begin{array}{l}\text { Periodo: no hay } \\
\text { Iniciativa: Intendente Regional } \\
\text { Aprobación: Consejo Regional por mayoría } \\
\text { Revisión: El sector (ministerio y/o servicio público) } \\
\text { Pronunciamiento: no considera }\end{array}$ \\
\hline
\end{tabular}

36 Ante la opción de una o más competencias a uno o más gobiernos regionales, en el tiempo se conforman regulaciones heterogéneas de la administración regional incluyendo en ello una diversidad institucional en la administración regional.

${ }^{37}$ Mensaje Presidencial No115-359 de fecha 12 de septiembre del año 2011 


\section{RTR \\ Revista Territorios y Regionalismos \\ N³, 2020, pp.61-81 \\ https://doi.org/10.29393/RTR3-5OHDR10005}

\begin{tabular}{|l|l|}
\hline Fortalecimiento de capacidades: no considera \\
Transferencia de competencias: se definen 3 formas, la primera: propone que el \\
gobierno regional con sus recursos podrá desarrollar, total o parcialmente, las \\
competencias señaladas, previo convenio con el ministerio y servicio público \\
aprobado por decreto supremo; la segunda, corresponderá a la transferencia de \\
programas a través de la administración y ejecución de programas previo acuerdo \\
con el ministerio y servicio aprobado por decreto supremo y finalmente a través \\
de la creación de servicios públicos regionales dependientes del intendente \\
regional. \\
$\begin{array}{l}\text { Decreto: Deberán consignar las competencias transferidas y las formas de cómo } \\
\text { se producirá la revocación anticipada de la competencia siendo justificada por la } \\
\text { deficiente prestación de servicios, ineficiencias e ineficacias e la asignación y } \\
\text { utilización de recursos públicos o interferencia de funciones y atribuciones con } \\
\text { otros órganos de la administración del Estado. }\end{array}$ \\
\hline
\end{tabular}

Fuente: Elaboración propia en base a Boletín 7963-06 que contiene Mensaje Presidencial 115-359 de septiembre del año 2011

\section{c) Propuesta del año 2015}

En el mes de enero del año 2015, el Ejecutivo, presenta una nueva propuesta, ésta toma como base el resultado del primer trámite constitucional del proyecto ingresado el año 2011, ello se realiza mediante mensaje presidencial ${ }^{38}$ (ver Recuadro $\mathrm{N}^{\circ} 3$ ) que incluye el mecanismo de transferencia de competencias. El nuevo mecanismo propone que la transferencia puede tener origen tanto en el Presidente de la República como en el gobierno regional y al interior de éste, la solicitud es originada por intendente regional, requiriendo la aprobación del consejo regional por $2 / 3$ de sus miembros en ejercicio. Se mantiene la opción de transferir atribuciones y programas, eliminando la opción de servicio público presente en la alternativa del año 2011. Se adiciona en la nueva propuesta la posibilidad de que el Presidente de la República transfiera competencias de iniciativa propia dejando el proceso de revocación incorporado en la propuesta del año 2011.

Recuadro N³: Procedimiento propuesto por el Ejecutivo en Enero del año 2015

\begin{tabular}{|l|l|}
\hline Materias & $\begin{array}{l}\text { Ordenamiento territorial; fomento de las actividades productivas; desarrollo } \\
\text { social y cultural }\end{array}$ \\
\hline Temporalidad & Indefinido y temporal según naturaleza \\
\hline Precursor del proceso & Presidente de la República y Gobierno Regional \\
\hline Reglamentación & $\begin{array}{l}\text { Reglamento del ministerio del interior y seguridad pública, suscrito además } \\
\text { por los de hacienda y segpres }\end{array}$ \\
\hline $\begin{array}{l}\text { A solicitud del } \\
\text { gobierno regional }\end{array}$ & $\begin{array}{l}\text { Periodo: Indefinido } \\
\text { Iniciativa: Intendente Regional o Consejo Regional } \\
\text { Aprobación: Mayoría, en caso que el intendente regional y el consejo regional } \\
\text { coincida en acuerdo o 2/3 de consejeros regionales en ejercicio si hay } \\
\text { diferencias. }\end{array}$ \\
\hline
\end{tabular}

${ }^{38}$ Mensaje Presidencial 1169-352 del mes de enero del año 2015 


\begin{tabular}{|c|c|}
\hline & $\begin{array}{l}\text { Revisión: Comisión integrada por ministerio del interior, hacienda, segpres, } \\
\text { ministerio sectorial, director de servicio, la Subdere actúa como secretaría } \\
\text { ejecutiva. } \\
\text { Pronunciamiento: } 90 \text { días extensibles a } 12 \text { meses, en caso que, la comisión } \\
\text { requiera antecedentes adicionales. } \\
\text { Fortalecimiento de capacidades: no considera } \\
\text { Transferencia de competencias: se podrá implementar de dos formas, la } \\
\text { primera mediante acuerdo con ministerio y servicio público, los recursos } \\
\text { requeridos serán transferidos mediante ley de presupuesto en la partida } \\
\text { correspondiente al gobierno regional. La segunda corresponderá vía } \\
\text { programa y para ello el gobierno regional podrá administrar y ejecutar } \\
\text { programas previstos en acuerdo con el ministerio y servicio público. } \\
\text { Decreto: deberán consignar las competencias transferidas y los recursos } \\
\text { necesarios para el ejercicio de la competencia adicionalmente los criterios de } \\
\text { renovación basada en su deficiente prestación de servicios, ineficiencias e } \\
\text { ineficacias en la asignación y utilización de recursos públicos pudiendo } \\
\text { solicitar la revocación por el Presidente de la República o el gobierno regional. }\end{array}$ \\
\hline $\begin{array}{l}\text { A propuesta de } \\
\text { Ministerios y Servicios } \\
\text { Públicos }\end{array}$ & $\begin{array}{l}\text { Periodo: Indefinido } \\
\text { Iniciativa: Ministerios y Servicios Públicos } \\
\text { Aprobación: Presidente de la República previa recomendación comité de } \\
\text { ministros y consulta al gobierno regional. } \\
\text { Pronunciamiento: no lo considera } \\
\text { Fortalecimiento de capacidades: no lo considera } \\
\text { Transferencia de competencias: En el caso de requerir modificaciones legales } \\
\text { el Presidente de la república solicita al Congreso Nacional autorización para } \\
\text { emitir decreto con fuerza de ley que permita transferir la competencia. En el } \\
\text { caso contrario, se podrá implementar de dos formas, la primera mediante } \\
\text { acuerdo con ministerio y servicio público, los recursos requeridos serán } \\
\text { transferidos mediante ley de presupuesto en la partida correspondiente al } \\
\text { gobierno regional. La segunda corresponderá vía programa y para ello el } \\
\text { gobierno regional podrá administrar y ejecutar programas previstos e acuerdo } \\
\text { con el ministerio y servicio público. } \\
\text { Decreto: Deberán consignar las competencias transferidas y los recursos } \\
\text { necesarios para el ejercicio de la competencia adicionalmente los criterios de } \\
\text { revocación basada en la deficiente prestación de servicios, ineficiencias e } \\
\text { ineficacias en la asignación y utilización de recursos públicos pudiendo } \\
\text { solicitar la revocación por el Presidente de la República o el gobierno regional. }\end{array}$ \\
\hline
\end{tabular}




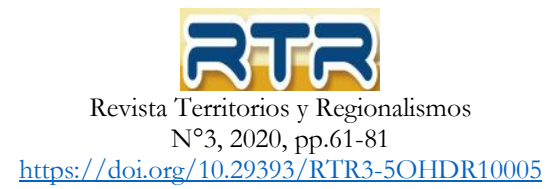

\section{3.- Bases constitucionales y normativas}

En plena discusión del proyecto ${ }^{39}$ que contenía el mecanismo para la transferencia de competencias, es ingresada a trámite una nueva propuesta de reforma constitucional ${ }^{40}$, posteriormente aprobada año 2017 consagrando la elección del gobernador regional. Ello lleva a discutir la validez del modelo de descentralización administrativa, dado que las sucesivas propuestas, se habían planteado siempre, en un contexto del modelo mixto bajo la premisa de la existencia de un intendente regional designado por el Presidente de la República y no podría ser utilizada idéntica lógica bajo la existencia de una nueva autoridad regional electa por sufragio universal. La importancia de este cambio enmarcado en un proceso de negociación política da origen a la incorporación del artículo vigésimo octavo transitorio en la constitución, donde se señala que, "La primera elección por sufragio universal en votación directa de los gobernadores regionales se verificará en la oportunidad que señale la ley orgánica constitucional a que aluden los incisos cuarto y quinto del artículo 111 y una vez promulgada la ley que establezca un nuevo procedimiento de transferencia de las competencias a las que se refiere el artículo 114". Es decir, supedita la elección del gobernador regional a la existencia de un nuevo procedimiento de transferencia de competencia, el que se definirá a posterior en la ley 21.074 de febrero del año 2018.

El nuevo procedimiento que viene a reemplazar los antiguos artículos 67 (vía ley) y 107 (vía convenio) de la ley 19.175 Orgánica Constitucional de Gobierno y Administración Regional, se basa en un nuevo marco constitucional y retoma la propuesta que la transferencia de competencia de ministerios y servicios públicos se realice mediante un decreto supremo denominado "decreto supremo de transferencia". Esta definición, se presenta como una de la medida más innovadora de la legislación chilena, en la cual, el Presidente de la Republica, cuando su objetivo es avanzar en la descentralización administrativa, podrá modificar las leyes que asignan facultades a los ministerios y servicios públicos por un decreto supremo de transferencia y asignarlas a uno o más gobiernos regionales, el nuevo procedimiento se reconoce en el párrafo dos del título I de la ley 19.175 compuesto por 8 artículos. El sistema lo ejemplificaremos más adelante en la figura $\mathrm{N}^{\circ} 1$.

En los cuatro primeros artículos, se puede apreciar definiciones generales sobre el procedimiento, tales como, que el origen de la transferencia de competencia corresponderá tanto al Presidente de la República como al gobierno regional; éstas podrán ser transferidas de forma temporal o definitiva a uno o más gobiernos regionales y provendrán de ministerios y servicios públicos. Se declararán inadmisibles todas aquellas solicitudes de nuevas facultades que no correspondan expresamente a las materias de ordenamiento territorial, fomento de las actividades productivas y desarrollo social y cultural. Igual definición realizará el gobernador regional, cuando considere que una propuesta proveniente del consejo regional no cumpla con el mandato constitucional. Se establece el principio de subsidiariedad ${ }^{41} \mathrm{o}$ de proximidad como criterio de priorización para la decisión sobre competencias a transferir, señalando expresamente "toda aquella competencia con clara identificación regional, cuyo ejercicio en dicho nivel signifique una mejor calidad y oportunidad en la toma de decisiones y una mejor adecuación de la política nacional en el territorio, cuya transferencia no pueda ocasionar perjuicio a otras regiones, y potencialmente puedan ser ejercidas por la mayoría de aquellas, exceptuando los casos que por su naturaleza sea sólo aplicable a un determinado territorio".

\footnotetext{
${ }^{39}$ Boletín 7963-06

40 Reforma Constitucional Ley 20.990 (2017)

41 Artículo 21 quater de la ley 19.175
} 


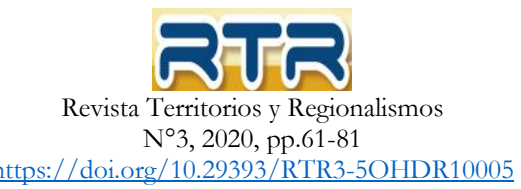

Los artículos que les siguen definen un procedimiento reglado, en el que participan los gobiernos regionales, no sólo como demandantes de competencias, sino también, como actores de veto para la transferencia de competencias, ello en el caso de las propuestas que realice el Presidente de la República o modificaciones propuestas por el Comité Interministerial de Descentralización.

$\mathrm{Al}$ interior del gobierno regional, también se reglamenta la estructura de decisiones entre el gobernador regional y el consejo regional, dado que este último podrá ejercer el rol de actor de veto ante las propuestas realizadas por el gobernador regional. Una solicitud de transferencia de competencia podrá ser modificada a propuesta de la comisión de estudio y consultado el gobierno regional podrá aceptar o rechazar dicha modificación. Una solicitud se entenderá rechazada, cuando exista un informe fundado del Presidente de la República sobre la no transferencia; cuando sea declarada inadmisible o en caso de un silencio administrativo mayor a 180 días. Sólo podrán ser revocadas las competencias que hayan sido definidas como temporales y fundadas en los siguientes casos: a) el incumplimiento de las condiciones que se hayan establecido para el ejercicio de la competencia; b) deficiente prestación del servicio a la comunidad; y c) el ejercicio incompatible con las políticas nacionales. La revocación puede ser definida tanto por el Presidente de la República como una solicitud realizada por el Gobierno Regional.

Figura N`1: Flujo del Procedimiento de Transferencia de Competencias 


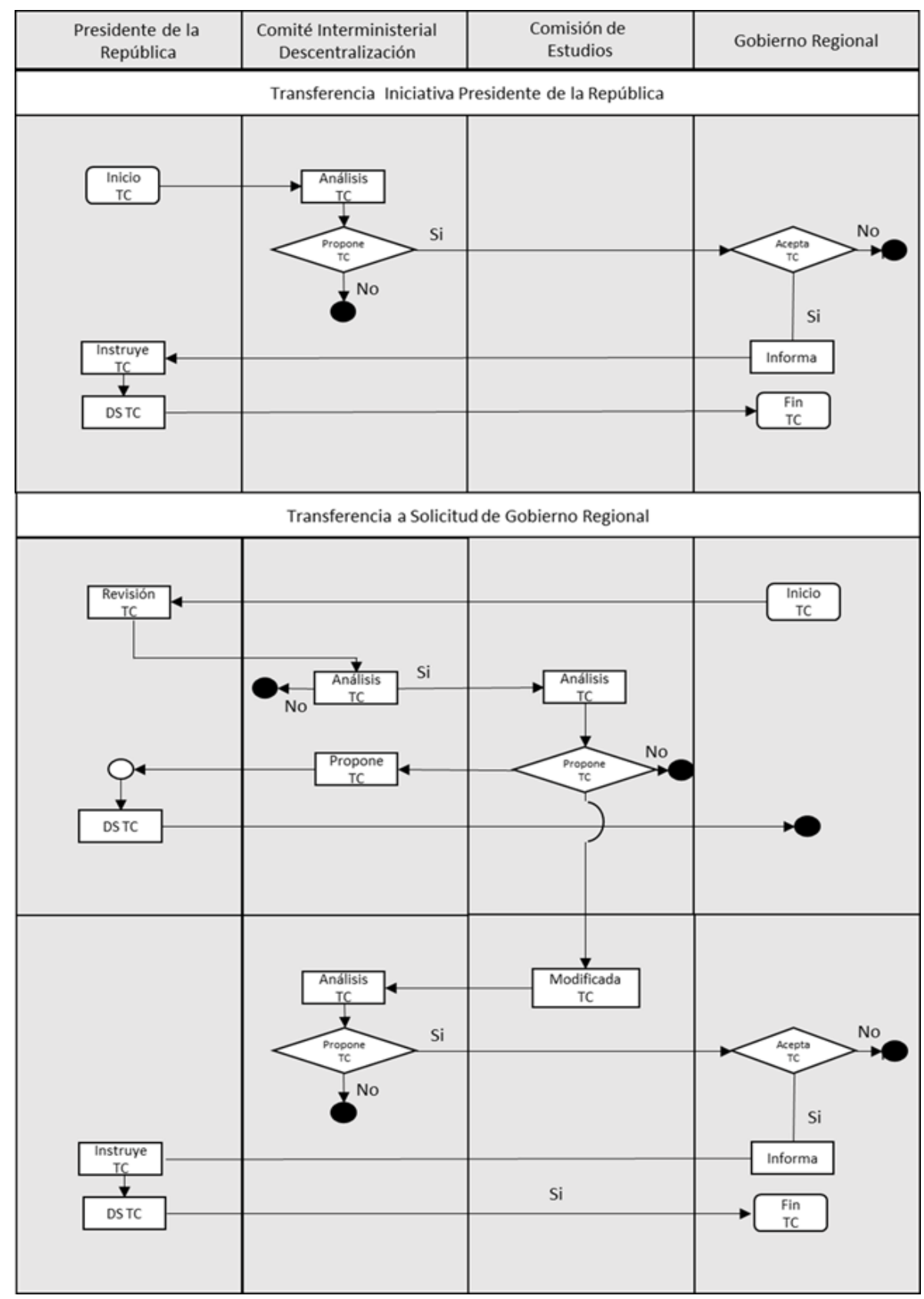

Fuente: Elaboración propia, basado en ley 19.175 modificada por ley 21.074; TC= Transferencia de Competencias

El mecanismo vigente ${ }^{42}$ se iniciará con una solicitud de transferencia, la cual, podrá ser ejercida a partir de la investidura del Presidente de la República y por un período de 24 meses y deberá ser resuelto por el Presidente en el lapso de 180 días para cada solicitud de competencia, sea este iniciado por una solicitud

42 En la actualidad el procedimiento no ha sido aplicado, dado que las leyes plantean una gradualidad entre los años 2018 y 2022. 


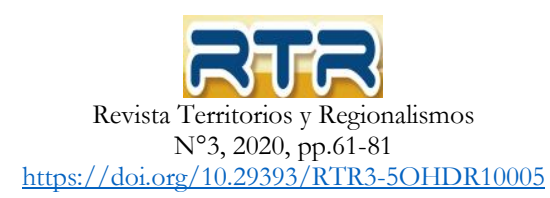

del gobierno regional o el Presidente de la República de oficio. El procedimiento se regirá por un reglamento aprobado por un decreto supremo emitido por el ministerio del interior y seguridad pública. La competencia será transferida a través de un decreto de transferencia ${ }^{43}$ en el cual se define según lo señalado en el artículo 21 sépties "la o las competencias y recursos que se transfieren; la indicación de temporalidad; la gradualidad con que aquella se transfiere y las condiciones con que el gobierno regional deberá ejercerlas, mencionando si dicho ejercicio será exclusivo o compartido con el nivel central, delimitando en este último caso las acciones que a cada uno de los actores competa; la forma en que se hará el seguimiento al ejercicio de la transferencia efectuada; y todas aquellas especificaciones para asegurar el adecuado ejercicio de la competencias transferidas". El decreto supremo de transferencia resultante, formará parte de la estructura legal de competencia del gobierno regional.

\section{4.- Cambio institucional y perspectivas}

\subsection{La descentralización administrativa y el régimen de competencias de los gobiernos regionales}

El nuevo régimen de competencias de los gobiernos regionales se basa en las funciones y atribuciones actuales que se otorgan a través de la ley ${ }^{44}$. Este se divide en funciones de carácter general; facultades de carácter específico, tales como, materias de ordenamiento territorial, fomento productivo, desarrollo social y cultural; y las atribuciones que permiten su ejercicio. La ejecución de dichas competencias se debe entender como un ejercicio compartido con los órganos del gobierno central, principalmente con los servicios públicos, dado que el gobierno regional según la nueva ley podrá desarrollar éstas directamente o con la colaboración de otros órganos de la administración del Estado ${ }^{45}$. Un aspecto relevante en el nuevo marco normativo es la asignación de la competencia residual al gobierno regional, al permitir ejercer todas las atribuciones necesarias para el ejercicio de las funciones que las leyes le encomienden ${ }^{46}$. Por otra parte, se considerarán como competencias exclusivas, aquellas relacionadas con la elaboración del proyecto de su presupuesto y la distribución de los recursos que correspondan a su patrimonio, tendrán igual cualidad la elaboración y aplicación de políticas, planes, programas y proyectos de desarrollo de la región.

La rectoría de las competencias del gobierno central, tanto en materia financiera como las del desarrollo, queda de manifiesto cuando se señala que el gobierno regional deberá enmarcarse en lo definido por DL 1.263/1975 orgánica de la administración financiera del Estado y al presupuesto de la nación. En materia del desarrollo, se plantea que todas aquellas materias consignadas, tanto las actuales, como las que le sean transferidas serán ejercidas en forma coherente ${ }^{47}$ con las políticas públicas nacionales y sus reglamentos. Finalmente se señala que las competencias atribuidas a los gobiernos regionales no afectarán las funciones y atribuciones que corresponda a la administración pública nacional, en todo aquello que no haya sido encomendado.

El gobierno regional, en su nuevo marco legal, cuenta con competencias de planificación, asignación y ejecución, la primera es ejercida a través de la elaboración y aprobación de políticas regionales que

\footnotetext{
43 Artículo 21 letra C

44 DFL1-19175 (2005) Orgánica Constitucional de Gobierno y Administración Regional.

45 Artículo 106 DFL 1- No19.175 (2005)

46 Artículo 20 DFL 1-No19.175 (2005)

${ }^{47}$ La coherencia se define como: cuando en el ejercicio de las atribuciones del gobierno regional no contradiga las políticas públicas nacionales y sea compatible con los principios o definiciones establecidas en aquellas.
} 


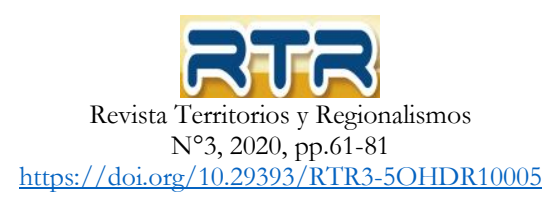

integran planes (convenios de programación y territoriales), programas y proyectos ${ }^{48}$. La segunda, corresponde a la asignación de recursos a través de la formulación y aprobación de su proyecto de presupuesto, así como la distribución de sus recursos asociados a sus programas de inversión y finalmente con la ejecución de programas y proyectos a través de sus unidades especializadas ${ }^{49}$ o entidades técnicas de la administración del Estado a través de convenios mandatos o de transferencia ${ }^{50}$. De igual forma será considerado parte del régimen competencial de los gobiernos regionales, todas aquellas facultades y atribuciones que le sean transferidas mediante decreto supremo de transferencia en el proceso definido en el párrafo 2 de la transferencia de competencias.

\subsection{La descentralización política y el régimen electoral}

La descentralización política comprenderá las elecciones regionales, en este caso, el gobierno regional está integrado por el consejo regional y el gobernador regional, ambos elegidos por sufragio universal, el primero, a raíz de la reforma constitucional del año 2009 (ley 20.390) y la ley 20.678 del año 2013 que habilita su elección, en el mismo año se realiza la primera elección. El gobernador regional será electo a partir del año 2020 precepto que se configura en la reforma de la constitución del año 2017 (ley 20.990) y la ley 21.073 del año 2018 que la regula. El sistema electoral a nivel regional tiene entre sus principales contenidos que cuando entre en régimen, las elecciones se realizarán el último domingo ${ }^{51}$ del mes de octubre cada 4 años en conjunto con las elecciones municipales (de alcaldes y concejales), lo que se ha denominado en la discusión parlamentaria como "elecciones territoriales". En el caso particular del gobernador regional, se ha considerado realizar una segunda vuelta y si ningún candidato obtenga más del $40 \%$ de los votos válidamente emitidos en primera vuelta, en la segunda vuelta será electo aquel que en dicha oportunidad saque la mayoría entre las dos primeras mayorías relativas.

Es importante consignar entonces que, el sistema de elección del consejo regional se realiza por sufragio universal en elección directa, los consejeros regionales postulan en circunscripciones provinciales ${ }^{52}$, por regla general, la circunscripción corresponderá a la provincia, exceptuando las provincias de Valparaíso, Cachapoal, Concepción, Cautín y Santiago. La representación en la región deberá mantener el principio de equidad territorial y tendrá tantos consejeros regionales como población tenga la región, número que va desde 14 miembros cuando la región tiene una población inferior a 400 mil habitantes hasta 34 cuando la región sobrepasa los 4 millones de habitantes. La distribución de los curules por circunscripción se realizará bajo el principio de equidad territorial al distribuir la mitad de los escaños disponibles por el número total de circunscripciones provinciales y el saldo restante se distribuirá proporcionalmente por el sistema de cifra repartidora. El director del servicio electoral es el responsable y por resolución definirá el número de consejeros a elegir y su distribución por circunscripción las que serán definidas 6 meses antes de la elección.

La elección de los consejeros regionales ha ocurrido, se han elegido ininterrumpidamente desde el año 1993 elección que se efectuaba en el mes de diciembre del año de las elecciones municipales. En las elecciones del año 2013 y 2017 fueron electos por la ciudadanía por sufragio universal en conjunto con

\footnotetext{
48 SUBDERE (2010)

${ }^{49}$ Entidades especializadas del gobierno regional corresponden a las divisiones de fomento e industria, desarrollo social y humano y la división de infraestructura y transporte.

50 Artículo 81, 81 bis y 81 ter DFL 1-19.175 actualizada por ley 21.074 (2018)

${ }^{51}$ Existirá un periodo de transición que considera la elección el año 2020 solo de la elección del gobernador regional, el año 2021 se realizará la elección de los consejeros regionales y su cargo estará vigente hasta el 5 de enero del año 2025

52 La provincia de Valparaíso se divide en 2, a provincia de Cachapoal en 2, la provincia de Concepción se dividirá en 3, la provincia de Cautín en 2 y la de Santiago en 6 circunscripciones.
} 


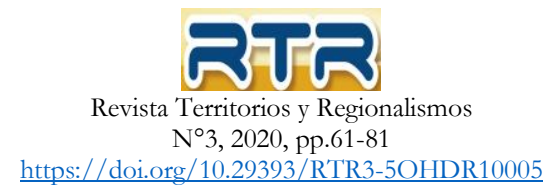

las elecciones parlamentarias. La próxima elección ocurrirá el año 2021 y será la última que ocurra en conjunto con las elecciones presidenciales, a partir de allí, se efectuará en conjunto con las elecciones municipales (ley 19.175 art. 83). La primera elección conjunta con el gobernador regional ocurrirá en el mes de octubre del año 2024 aplicándose al gobernador regional el sistema de elección primaria definido en la ley 20.640 lo que no regirá para la elección de consejeros regionales.

Las declaraciones de candidaturas de los consejeros regionales solo podrá ser declarada ante el director del servicio electoral, o el respectivo director regional del mismo servicio en un solo acto respecto de cada circunscripción provincial y deberá efectuarse por el presidente y secretario del órgano ejecutivo de cada partido político o conjunto de partidos que hubieran acordado un pacto electoral, dicho pacto podrá contener sub-pactos y candidaturas independientes, debiendo estar vigente al momento de la inscripción.

En el caso de las candidaturas independientes fuera de pacto deberá concurrir con a lo menos, cinco de los ciudadanos que hayan patrocinado la candidatura independiente acompañado de la nómina de patrocinantes ${ }^{53}$. El escrutinio general y la calificación de las elecciones se realiza por el Tribunal Electoral Regional. El sistema de elección y de distribución de escaños se basará en el de cifra repartidora ${ }^{54}$ y de lista abierta. La asignación de escaños a la lista está asignada por la cifra repartidora y al interior de la lista el criterio es el número de sufragios, conformándose las listas por a) partidos que formen pacto; b) los partidos fuera de pacto y c) cada uno de los independientes que no integren un pacto.

El régimen electoral correspondiente a la elección del gobernador regional y su marco legal está definido en la ley 19.175 y supletoriamente las leyes orgánicas constitucionales de votaciones populares y escrutinios; de partidos políticos y sobre sistema de inscripciones y servicio electorales. Particularmente la candidatura a gobernador regional podrá ser declarada por un partido político, por un pacto de partidos, por un pacto entre un partido político e independientes, por un pacto de partidos e independientes, y por independientes. En el caso de ser una candidatura independiente deberá presentar un listado de patrocinantes superior al $0,5 \%$ de los votos emitidos en la elección ${ }^{55}$ de gobernadores regionales inmediatamente anterior. Estará sometido al sistema de requisitos, inhabilidades e incompatibilidades señalados en el recuadro $\mathrm{N}^{\circ} 5$.

La nominación de candidatos a gobernador regional se someterá al régimen de elecciones primarias, según las normas definidas en la ley 20.640, ello implicará que, cuando lo determinen los partidos políticos, a través de sus organismos internos y en conformidad a sus estatutos podrán participar en proceso de elección primaria. Dicha elección deberá realizarse con carácter nacional el vigésimo domingo ${ }^{56}$ anterior a la fecha de las elecciones municipales. La elección de gobernadores regionales estará sometida al escrutinio general y de calificación del Tribunal Calificador de Elecciones diferenciándolo del proceso eleccionario del consejo regional, que lo lleva el TRICEL Regional. Se incorpora en la elección de

\footnotetext{
53 De acuerdo al artículo 89 de la ley 19.175 el porcentaje de patrocinantes de las candidaturas a consejeros regional deberá corresponder al $0,5 \%$ de los electores que hayan sufragado en la elección popular más reciente en la circunscripción provincial respectiva, siendo responsabilidad definirla al director del Servicio Electoral mediante resolución publicada en el DO, con siete meses de anticipación de la fecha de realización de la elección.

${ }^{54} \mathrm{La}$ cifra repartidora se obtiene al sumar los votos obtenidos por la lista y divididos por el número de escaños a repartir, este procedimiento se realizar para todas las listas participantes en la elección, la resultante es ordenada de mayor a menor, corresponderá al valor de la cifra repartidora aquel que se obtenga en la posición del número de escaños. Finalmente, el número de electos por la lista corresponderá a la división del total de votos por la cifra repartidora. En el caso de que existan subpactos en la lista se distribuirán por cifra repartidora sobre el total de escaños asignados a la lista.

55 Para la primera elección se requerirá...

56 Para la primera elección corresponderá al día 7 de junio del año 2020, las elecciones municipales corresponderán al 25 de octubre del año 2020
} 


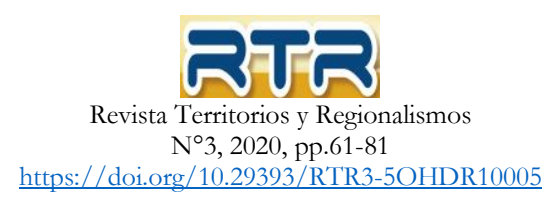

gobernadores regionales un voto programático aminorado, ello significa que será requisito para ser candidato presentar un programa en el que se indicarán las principales acciones, iniciativas y proyectos que pretenden desarrollar durante su gestión no concurriendo su obligatoriedad en el cumplimiento.

Será gobernador regional electo, aquel candidato que haya obtenido la mayoría de los sufragios válidamente emitidos y siempre que dicha mayoría sea equivalente, al menos, al $40 \%$ de los votos válidos ${ }^{57}$. Si ninguno de los candidatos a gobernador regional obtuviere la mayoría se procederá a una segunda votación el cuarto domingo después de la votación original, en la que participarán las dos más altas mayorías relativas y en dicha elección saldrá electo aquel que haya tenido el mayor número de sufragios. El gobernador y su consejo regionales se instalarán el día 6 de enero del año siguiente de la elección respectiva, donde se procederá a tomar juramento y posesión convocados para tal efecto por el secretario ejecutivo del consejo regional.

\subsection{Descentralización Fiscal}

El tercer tópico que permite describir el modelo de descentralización territorial corresponde a la descentralización fiscal, ello ocurre cuando las competencias fiscales (ingresos y gasto público) se desplazan del nivel superior ${ }^{58}$ o central hacia el inferior o subnacional y constituye, por lo general, un proceso dirigido desde el nivel central. En el caso de Chile, el gobierno regional en el nivel subnacional, es parte del sistema de administración financiera del Estado regulado por el DL 1.263/1975 Orgánica Constitucional de Administración Financiera del Estado y se podría señalar que la descentralización observada se distingue preferentemente por la delegación de competencia de gasto público.

El modelo de descentralización fiscal se construye a partir del modelo definido en el año 1974 (DL Nº575) y el año 1975 en materia financiero-presupuestaria (DL. No1.263), retomada por la constitución de 1980 profundizada por la reforma constitucional de 1991 en base a dos preceptos definidos en la constitución, el primero regido por el artículo $\mathrm{N}^{\circ} 19 \mathrm{~N}^{\circ} 20$ que permite gravar actividades o bienes que tengan clara identificación regional y que estos puedan ser aplicados por autoridades regionales o comunales y el segundo, corresponde a lo señalado por el artículo 115 al definir que una proporción del total de los gastos de inversión pública será transferido a los gobiernos regionales mediante la ley de presupuestos del sector público y se denominará Fondo Nacional de Desarrollo Regional. Ambos estructuran el sistema de financiamiento de los gobiernos regionales.

Dado el marco definido en el párrafo anterior, se puede señalar que el comportamiento que ha tenido el financiamiento de los gobiernos regionales, en relación, al volumen de recursos administrados se ha mantenido constante moviéndose en una franja que oscila entre el 2,6 y 3,1\% respecto del gasto público en el periodo que va desde el año 2007 al año 2017. Por otro lado, en relación, a la composición de los ingresos en función de su naturaleza se tiene que los recursos asociados al artículo 115 de la constitución (FNDR) el año 2007 ascendían al 46,8\% llegando al 33,9\% el año 2017 y los recursos cuya naturaleza tiene como origen el artículo $19 \mathrm{~N}^{\circ} 20$ en el mismo período va desde un $6,4 \%$ a un $42 \%$. El resto de los recursos administrados por el gobierno regional corresponden a recursos definidos en la ley de presupuestos conocidos como provisiones que se definen como transferencias condicionadas ${ }^{59}$. El año 2011 se modificó la medida del FNDR al independizarlo de los ingresos propios y asignados por ley.

${ }^{57}$ Los votos blancos y nulos se considerarán como no emitidos.

58 Aghon G. (1993)

${ }^{59}$ SUBDERE (2018) 


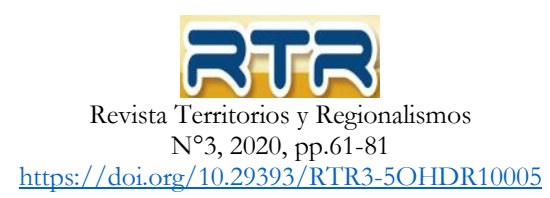

También se puede considerar la capacidad de decisión de los gobiernos regionales respecto del presupuesto de inversión pública ${ }^{60}$ el año 2016 ascendió a un 24,8\%.

\section{5.- Conclusiones}

La regionalización en Chile ya tiene 45 años, en el transcurso de este periodo, se ha podido observar cambios sustantivos en la estructura y organización del poder territorial. Es posible reconocer en este cambio, tres modelos de administración regional cuyo origen y diseño se verifica en las reformas constitucionales. El modelo regional desconcentrado que se desarrolla entre los años 1974 y 1991, basado en una estructura jerárquica y dependencia nacional; el modelo de administración regional mixto que transcurre entre los años 1991 y 2017, caracterizado por la descentralización administrativa; y el modelo descentralización territorial a partir del año 2017, caracterizado por la profundización de la descentralización política.

Es posible apreciar que el diseño original de la administración regional, planteado en la constitución, corresponde a una estructura y organización descentralizada territorialmente, sin embargo, la misma constitución en un principio limitó su desarrollo o fue excesivamente restrictiva. Al principio fusionando las funciones de gobierno y administración regional asignándolas al intendente regional. Seguida por un nuevo diseño, igualmente restrictivo, en el que se asigna la función de administración regional al gobierno regional, donde la primerísima autoridad sigue en manos del intendente regional, que también detenta la función de gobierno interior en la región. Ello evoluciona en la última reforma constitucional revisada, a la separación de la relación jerárquica entre el nivel central y el gobierno regional, a través del cambio de la figura del intendente regional por la del gobernador regional electo por sufragio universal.

Es posible sistematizar el diseño o ingeniería constitucional de la administración regional actual, considerando la descentralización política propuesta por la reforma constitucional del año 2017, la profundización de la descentralización administrativa establecida en la reforma del año 2009 y la consolidación del modelo de administración financiera regional de la reforma del año 1991, ello configura el modelo de descentralización territorial. Lo anterior denota la ruptura de las relaciones de jerarquía preexistentes, transferencia de poder político a las autoridades electas por la ciudadanía y poder administrativo a través del sistema de transferencia de competencias.

El proceso de descentralización administrativa llama nuestra atención particularmente, dado que, en su diseño incorpora el principio de heterogeneidad institucional, cuya primera propuesta e intento de reforma constitucional se realiza el año 2003, continuando con las propuestas realizadas en los años 2008, 2011, 2015 y su sanción final con la reforma del año 2009. Predomina en las diferentes propuestas presentadas que la descentralización administrativa, se realice a través de la transferencia de competencias, elemento que permite la modificación de la organización y estructura de la administración pública y ella se ejecute mediante un proceso reglamentario (decreto supremo) convirtiéndose en una excepción a la regla general que la creación, supresión o modificación de la estructura de la administración pública es materia de ley. Forma y modo ya utilizado con anterioridad en el proceso de descentralización municipal de los años 80 (DFL1-3.063).

\footnotetext{
${ }^{60}$ MIDESO (2016)
} 


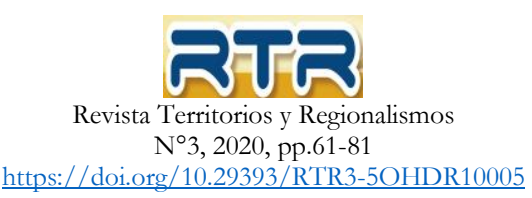

\section{Referencias Bibliográficas}

Aghon G. (1996). Descentralización fiscal en América Latina, balance, retos y perspectivas. CEPAL

Barrios-Suvelza Franz. (2014). "The Case for Conceptual Dichotomies in Comparative Federalism: Can Polítical Science Learn from Compartive Constitutional Law?". Territorial, Politic, governance, (Vol. №2 $\mathrm{N}^{\circ} 1$ ), pp. 3-29, pag. 15 y 19.

Carrasco Delgado Sergio. (1997). "Iniciativa sobre descentralización y regionalización durante el periodo de vigencia de la constitución de 1925”. Revista Chilena de Derecho, (Vol. N²4 No2), pp. 321-335.

Cea Egaña José Luis. (1997). "Hacia el Estado Regional en Chile, Revista Chilena de Derecho”, (Vol. No $\left.24 \mathrm{~N}^{\circ} 2\right)$, pp. 337-351.

Daughters Robert. \& Harpers Leslie. (2007): "Reformas de descentralización fiscal y política", en Cap. 7. El estado de las reformas del Estado en América Latina. (Ed. Eduardo Lora, BM, BID, Ed. Mayol: Washington). Pp. 243 - 296.

Falleti Tulia (2010): Decentralization and Subnational Political in Latin America. New York: Cambridge University Press.

Hernández Olmedo Luis. (1993), "La Descentralización en el Ordenamiento Constitucional Chileno". Revista Chilena de Derecho. (Vol. No 20), pp. 535-555.

Nogueira Alcalá Humberto. (1985). "El Estado unitario, los procesos de descentralización regional y el Estado federal”. Revista Eure, (Vol. No12, No 34-35), pp. 135-143.

Mardones Rodrigo. (2006), "Descentralización y transición en Chile”, Revista de Ciencia Política, (Vol. No26 No1). Pp. 3-24.

Navarrete Bernardo. (2014). "Chile desde la teoría secuencial de la descentralización, 1990-2010". Convergencia, Revista de Ciencias Sociales. (N66), pp. $179-202$.

OCDE (2015). Chile: prioridades de política para un crecimiento más fuerte y equitativo, Serie: "Mejores políticas".

Tsebelis George. (2018). "Jugadores de veto y cambio constitucional: ¿se puede desbloquear la constitución de Pinochet?”. Política y Gobierno. (Vol. N²5 Nº1), pp. 3-30.

Cheema Shabir \& Rondinelli Dennis. (2007). Decentralizing Governance, Emering Conepts and Practice. Brookings Institution Press: Washington D.C.

SUBDERE (2018): Informe Anual de la Descentralización 2017

NORMAS JURÍDICAS CITADAS

Boletín Legislativo No5872-06, Gobierno y Administración Regional, Ley Chile BCN, 2018 


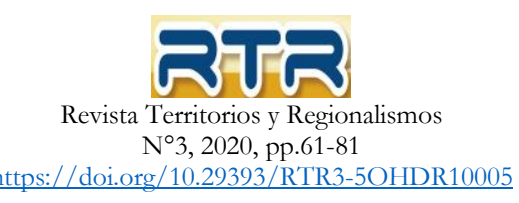

Boletín Legislativo No 7963-06, Fortalecimiento de la Regionalización, Ley Chile BCN, 2019

Boletín Legislativo No 11.200, Regula la Elección del Gobernador Regional, Ley Chile BCN, 2019

DL 573. Estatuto del gobierno y administración interiores del Estado,1974. Ley Chile BCN 2019

DL 575. Regionalización del País, 1974. Ley Chile BCN 2019.

DL 1.263 Orgánica de Administración Financiera del Estado, 1975. Ley Chile BCN 2019

Ley 19.097. De gobiernos regionales y administración comunal, 1991. Ley Chile BCN 2019.

Ley 19.175. Orgánica Constitucional de Gobierno y Administración, 1992, Ley Chile BCN 2018.

Ley 20.035. Incorpora nuevas funciones a los gobiernos regionales, 2005. Ley Chile BCN 2019.

DFL1/19.175. Coordinada y sistematizada de ley orgánica constitucional de gobierno y administración 2005, Ley Chile BCN 2019.

Ley 20.050. Introduce las siguientes modificaciones a la Constitución Política de la República, 2005. Ley Chile BCN (2019).

Ley 20.390. Reforma Constitucional En materia de gobierno y administración regional 2009, Ley Chile BCN (2019).

Ley 20.678. Establece la Elección Directa de los Consejeros Regionales, 2013, Ley Chile BCN 2019.

Ley 20.757. Dispone funciones y atribuciones del Presidente del Consejo Regional, 2014. Ley Chile BCN 2019.

Ley 20.990. Reforma Constitucional Dispone la Elección del Órgano Ejecutivo del Gobierno Regional, 2017. Ley Chile BCN 2019.

Ley 21.073. Regula la elección de gobernadores regionales, 2018, Ley Chile BCN 2019

Ley21.074. Fortalecimiento la regionalización del país, 2018. Ley Chile BCN 2018.

Mensaje Presidencial 115-359/2011, BCN, 2018

Mensaje Presidencial 1169-352/2015, BCN, 2018 